\title{
Experimental Analysis of different shaped ribs on heat transfer and fluid flow characteristics
}

\author{
Sandeep S Kore ${ }^{1}$,Sunil V. Dingare ${ }^{2}$, Satish Chinchanikar ${ }^{1}$, Pravin Hujare ${ }^{1}$ and Ashok Mache \\ ${ }^{1}$ Vishwakarma Institute of Information Technology, Pune (India) \\ ${ }^{2}$ MIT ADT University, Pune(India)
}

\begin{abstract}
There are number of applications such as gas turbines, solar air heating, electronics cooling and heat exchangers, where internal cooling passage is observed. For heat transfer augmentation inside these cooling passages different techniques are used like dimpled surface, wings and ribs. Ribs are used in most of the devices for internal cooling. The ribs disturb the boundary layer and increase the turbulent kinetic energy which enhances the heat transfer rate. Most of the researchers concentrate on square and rectangular shaped ribs. The cross section of the rib plays important role in the production of flow field. The shape of ribs affects on boundary layer separation, attachment and hot spots created. In the present paper heat transfer and fluid flow characteristics from rib roughened rectangular duct with different shapes of ribs were investigated. The experimental set up consists of rectangular channel of aspect ratio 4. The pitch to width ratio was varied as 5, 7.5 and 10 respectively. The Reynolds number was varied as 6000 to 30000 . The ribs used for the investigations were square, house and boot shaped. From the investigations it is observed that boot shaped rib is having higher thermal performance than other two geometries
\end{abstract}

\section{Introduction}

The output in terms of efficiency \& power of any thermal device increases by increasing turbine inlet temperature. In gas turbines efficiency can be improved by increasing turbine inlet temperature. The present turbine blades are exposed to temperature near about $1800 \mathrm{~K}$, which is higher than their melting temperature. To keep the temperature within working limit internal vanes and blades need to be cooled to lower the turbine blade temperature. For using any heat transfer enhancement technique it is important to know about boundary layer formation and higher temperature gradient spots. Otherwise higher temperature gradient cause thermal stresses and may cause decrease in life of turbine blade. The turbine blades and vanes are cooled by internal passage in which different turbulators are used to augment the heat transfer.

There are a wide range of cooling methods available and used in the gas turbine industry. Two categories exist when it comes to cooling methods, internal and external. An example of external cooling is the use of pushing air through blades and out, creating a cooler "film" over the blade and an example for internal cooling include passing relatively cooler air through the blade cavities. There are several specific methods of cooling, have been studied and implemented.

These methods take advantage of manufactured cavities, holes, etc. on the blade to improve heat transfer from the blade. With better heat transfer, higher inlet temperatures are able to be reached and thereby improving thermal efficiency and performance.

Film cooling uses coolant to create a boundary layer over the airfoil. On the airfoil itself, there are holes where the coolant, after entering the blade, is pushed out of these holes and creates this layer which acts as a barrier. This layer protects the blade and keeps it cooler than without the film.

Researchers have investigated internal cooling passage using various heat transfer augmentation techniques likes dimpled surface, twisted tape, flow blockage and ribs $[1,2]$. The various ribs investigated up till know are of square, isosceles triangular, reverse right-angle triangular, right angle triangular, right-angle trapezoidal, isosceles trapezoidal, and semicircular rib shapes [3]. But rib shapes like boot shape, house shape and pentagonal shape [3]were studied numerically. In present experimental work house shape and boot shaped ribs are investigated experimentally.

\section{Experimental setup details}

The experimental setup was designed keeping in view the validation of the smooth channels with considering results of Dittus-Boelter and modified Blasius correlations for smooth channels as shown in Fig.1 The experimental arrangement consists of 1 HP capacity blower to get the required flow rate. The test section is

Corresponding author: sandeep.kore@viit.ac.in 
manufactured from $10 \mathrm{~mm}$ epoxy resin. The dimensions of the test duct are $1150 \mathrm{~mm} \times 100 \mathrm{~mm} \times 25 \mathrm{~mm}$. The inlet and out sections are provided for hydro dynamically fully developed flow and to avoid eddies at outlet. To measure pressure drop across the test section two pressure taps are used. Fig. 2 shows test section.

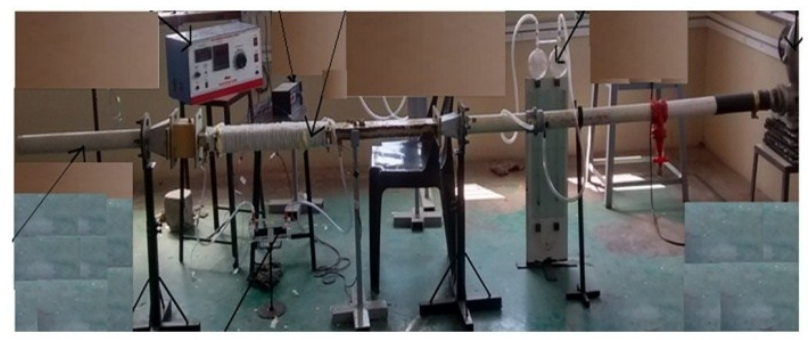

Fig.1 Experimental set up

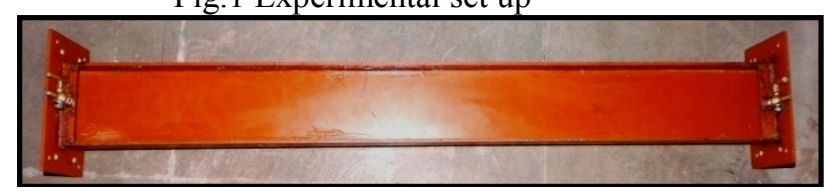

Fig.2 Test duct for experimental investigations

The test plate is of dimension $60 \mathrm{~mm} \times 108 \mathrm{~mm} \times 6 \mathrm{~mm}$. On the test plate ribs are pasted using metal glue. There are six ' $\mathrm{T}$ ' types thermocouples are used to measure the temperature of test plate and two are used to measure the temperature of the air. The plate type of heater is used for constant heat flux boundary condition. Figure 3, shows the ribs used for experimental investigations. It includes square shaped, house shaped and boot shaped rib. The experimental analysis is carried out at $20 \mathrm{~mm}$, $40 \mathrm{~mm}$ and $50 \mathrm{~mm}$ pitch.
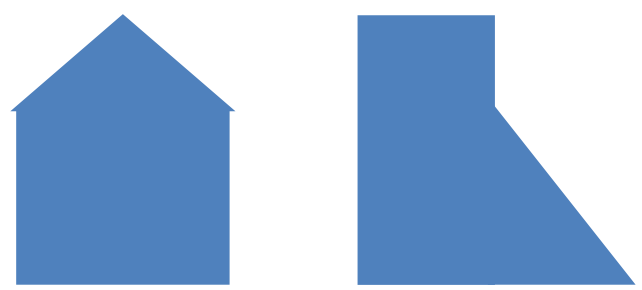

Fig.3. Schematics of ribs used in the present study

\subsection{Data reduction}

To measure the mass flow rate orifice meter is used connected to $U$ tube manometer with water as manometric fluid. The following relation is used to find the mass flow rate.

$$
\dot{m}=C_{D} a_{0} \times \frac{\rho_{\text {air } \times \sqrt{2 g H a}}}{\sqrt{1-\beta^{4}}} \quad(k g / s)
$$

Where,

$C_{D}=$ Coefficient of discharge for orifice,

$a_{0}=$ Cross sectional area of orifice $\left(\mathrm{m}^{2}\right)$,

$\beta=\mathrm{d} / \mathrm{D}$, diameter of pipe/ diameter of orifice $=0.8$, $\mathrm{g}=$ Acceleration due to gravity $\left(\mathrm{m} / \mathrm{s}^{2}\right)$,

$H_{a}=$ Height of air column (m).

Heat transfer to air can be calculated using following relation,

$$
\mathrm{Q}=\mathrm{mC}_{\mathrm{p}}\left(\mathrm{T}_{\mathrm{ai}}-\mathrm{T}_{\mathrm{ae}}\right)(\mathrm{Watt})
$$

Where,

$\mathrm{T}_{\mathrm{ai}}=$ Air temp at the inlet of the $\operatorname{duct}\left({ }^{\circ} \mathrm{C}\right)$,

$\mathrm{T}_{\mathrm{ae}}=$ Air temp at the exit of the $\operatorname{duct}\left({ }^{\circ} \mathrm{C}\right)$,

$\mathrm{m}=$ Mass flow rate of air $\left(\mathrm{kg} / \mathrm{s}^{2}\right)$,

Fig.1 Experimental set up

$\mathrm{C}_{\mathrm{p}}=$ Specific heat of air $(\mathrm{KJ} / \mathrm{kg} \mathrm{K})$,

$\mathrm{Q}=$ Convective heat transfer of air $(\mathrm{W})$.

The heat transfer coefficient for the test section

$$
h=\frac{Q}{A_{s} \cdot\left(T_{S}-T_{b m}\right)}\left(\frac{W}{m^{2} K}\right)
$$

Where

$\mathrm{h}$ = Convective heat transfer coefficient $\left(\mathrm{W} / \mathrm{m}^{2} \mathrm{~K}\right)$,

As $=$ Projected surface area of test surface, $\left(\mathrm{m}^{2}\right)$, $\mathrm{Ts}=$ Average temperature of the test surface, I,

$\mathrm{T}_{\mathrm{bm}}=$ Bulk mean temperature of air in the duct $=($ Tai + Tae $/ 2)\left({ }^{0} \mathrm{C}\right)$.

Nusselt number as,

$$
N u=\frac{h D_{h}}{K_{\text {air }}}
$$

Where,

$\mathrm{Nu}=$ Average Nusselt number of the test surface,

$D_{h}=$ Hydraulic diameter of the rectangular duct $(\mathrm{m})=0.04$,

$K_{\text {air }}=$ Thermal conductivity of air (W/mK).

The pressure drop across the test duct is determined by,

Where,

$$
\Delta \mathrm{P}=\left(\rho_{\mathrm{w}} * \mathrm{~g} * \mathrm{l}_{1} * \sin 1.25 * 13.5\right)(5)
$$

$\Delta P=$ Pressure Drop $(\mathrm{Pa})$

$\mathrm{g}=$ Acceleration due to gravity $\left(\mathrm{m} / \mathrm{s}^{2}\right)$,

$l_{1}=$ Manometer reading (manometer scale)

$$
f=\frac{(\Delta P) D_{h}}{2 \rho_{\text {air }} L V_{\text {air }}{ }^{2}}
$$

Where,

$$
\begin{aligned}
f & =\text { Friction factor } \\
\mathrm{D}_{\mathrm{h}} & =\text { Hydraulic diameter of the rectangular duct } \\
& =0.04 \mathrm{~m} . \\
\rho_{\text {air }} & =\text { Density of air }\left(\mathrm{kg} / \mathrm{m}^{3}\right) \\
L & =\text { Length of test plate }(\mathrm{m})
\end{aligned}
$$

\section{Results and Discussion}




\subsection{Validation of experimental set up}

The experimental set up is validated with Dittus-Boelter correlation for heat transfer as shown in Fig.4.The percentage deviation between theoretical and experimental value is below $6 \%$. For validation of friction factor modified Blasius correlation is used. The percentage deviation is below $9 \%$ as shown in Fig. 5

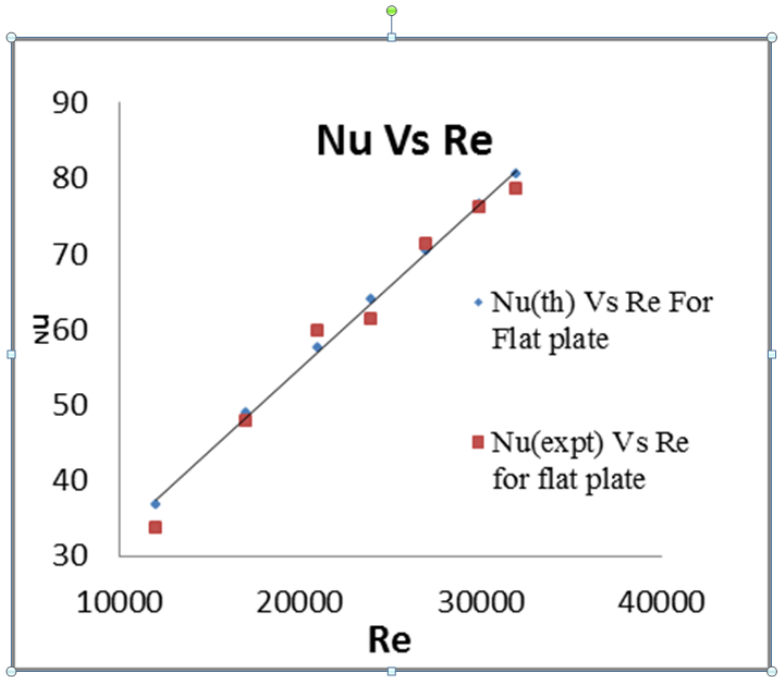

Fig.4. Validation of setup for heat transfer

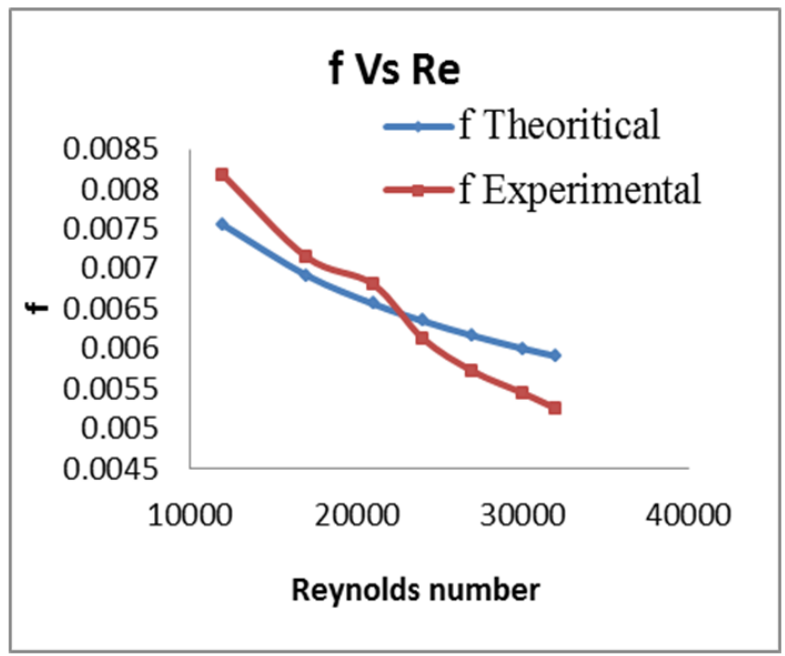

Fig.5. Validation of setup for friction factor

Figure 6, shows thermal performance for various shaped ribs. It is observed that at all Reynolds number thermal performance is higher. As Reynolds number increases thermal performance decreases from Reynolds number 18000 to 22000 . This may be due to transitional flow, after this thermal performance increases.

All the ribs with $40 \mathrm{~mm}$ pitch show highest performance. Compared to square, house shaped and boot shaped, performance of house shaped rib is higher. This is due to house shaped ribs reduces formation of recirculation zone behind and sharp edges causing the mixing of primary and secondary This results in turbulent mixing, which enhances the heat transfer rate. The performance of $20 \mathrm{~mm}$ pitch is lower due to chocking of the flow.

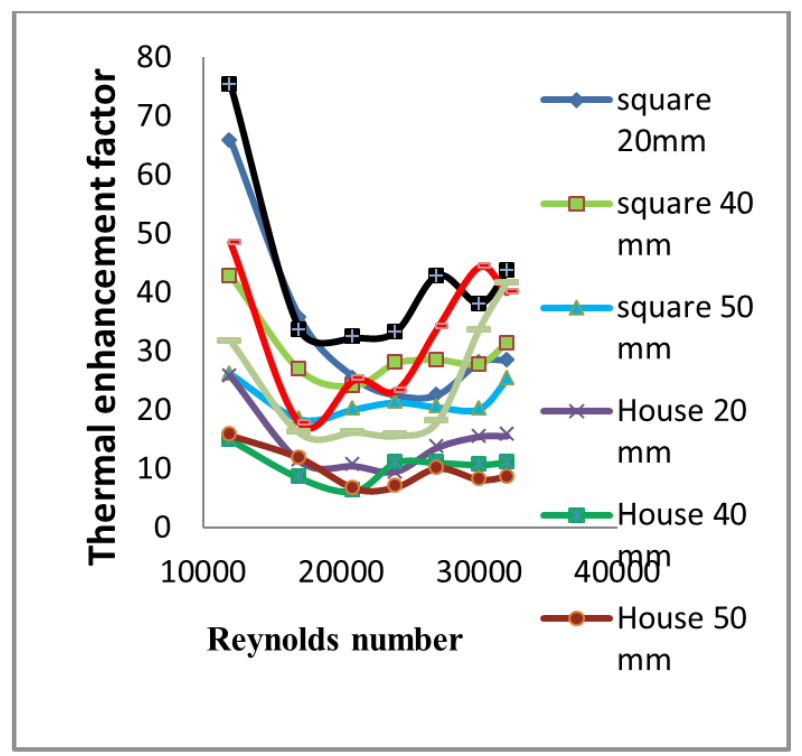

Fig.6. Thermal performance of différent ribs

\section{Conclusions}

The experimental investigation with different shaped ribs is presented in this paper. The pitch between the ribs and different shapes of ribs are the performance parameters. Following conclusions can be drawn from experimental analysis. The results show that performance of boot strap rib is higher than square and house shaped rib.

1. The performance of house shaped rib is lowest among all the ribs. The difference is due to the formation of recirculation zone behind rib. Recirculation zone is lowest for boot strap rib compared to house shaped rib. The recirculation zone is necessary for the ejection and mixing of the fluid.

2. Thermal performance results states that with respect to both Heat transfer and friction loss analysis Ribs with $40 \mathrm{~mm}$ pitch shows consistent high performance whereas boot shaped ribs with $20 \mathrm{~mm}$ pitch showed the highest performance

3. Comparing friction factor House shape ribs showed the lowest pressure drop whereas Boot shaped and Square ribs showed similar results.

\section{References}

1. Kore S.S., Yadav R.J. and Sane N.K., Investigations of Effect of dimple depth on heat transfer and fluid flow within rectangular 
channel"Procedia Engineering 125, 11101117(2015)

2. Kore S.S., Patil Adik and Sane N.K., Experimental investigation of the effect of flow blockages on heat transfer and fluid friction in a round tube using wallattached circular rings.,50,17-22(2019)

3. Mi-Ae Moon, Min-Jung Park, Kwang-Yong Kim Evaluation of heat transfer performances of various rib shapes" International Journal of Heat and Mass Transfer, 71, 275-284 (2014)

4. Robert Robert Kiml, Sadanari Mochizuki Akira Murata, Effects of Rib Arrangements on Heat Transfer and Flow Behaviour in a Rectangular RibRoughened Passage: Application to Cooling of Gas Turbine Blade Trailing Edge, Journal of Heat Transfer,123, 675-681(2001)

5. P.R. Chandra and C.R. Alexander, J.C. Han,Heat transfer and friction behaviors in rectangular channels with varying number of ribbed walls, International Journal of Heat and Mass Transfer, 46, 481-495(2003)

6. Hong-Min and Kwang-Yong Kim,Design optimization of rib-roughened channel to enhance turbulent heat transfer, International Journal of Heat and Mass Transfer, 47, 5159-5168(2004)

7. R. Kamali and A.R. Binesh, The importance of rib shape effects on the local heat transfer and flow friction characteristics of square ducts with ribbed internal surfaces, International Communications in Heat and Mass Transfer 35, 1032-1040(2008)

8. Pongjet Promvonge, Chinaruk Thianpong, Thermal performance assessment of turbulent channel flows over different shaped ribs, International Communications in Heat and Mass Transfer, 35 1327-1334(2008).

9. E. Elsaadawy,H. Mortazavi M. S. Hamed, Turbulence Modeling of Forced Convection Heat Transfer in Two-Dimensional Ribbed Channels" Journal of Electronic Packaging,130,031011-1031011-17(2008).

10. C. Thianpong, T. Chompookham, S. Skullong, P. Promvonge "Thermal characterization of turbulent flow in a channel with isosceles triangular ribs" International Communications in Heat and Mass Transfer 36, 712-717(2009)

11. Akhilesh P. Rallabandi, Huitao Yang ,Je-Chin Han, Heat Transfer and Pressure Drop Correlations for Square Channels With 45 Deg Ribs at High Reynolds Numbers, Journal of Heat Transfer,137, 071703-1 - 071703-10(2009)

12. Teerapat Chompookham, Chinaruk Thianpong, Sutapat Kwankaomeng, Pongjet Promvonge, Heat transfer augmentation in a wedge-ribbed channel using winglet vortex generators, International Communications in Heat and Mass Transfer, 37, 163-169(2010)

13. Huichun Liu, Jianhua Wang "Numerical investigation on synthetical performances of fluid flow and heat transfer of semiattached rib-channels" International Journal of Heat and Mass Transfer 54, 575-583(2011)

14. Akhilesh P. Rallabandi ,Nawaf Alkhamis, Je-Chin Han,"Heat Transfer and Pressure Drop measurements for a Square Channel With $45^{\circ}$ Round-Edged Ribs at High Reynolds Numbers, Journal of Turbo machinery, 133, 031019031029(2011).

15. M. I. Mohamed, R. Hoettiba, A. M. Saif, The Effect of the Corrugation Rib Angle of Attack on the Fluid Flow and Heat Transfer Characteristics Inside Corrugated Ribbed Passage, Journal of Heat Transfer, 133, 081901-10(2011).

16. Linqi Shui, Jianmin Gao, Xiaojun Shi,Jiazeng Liu, Effect of duct aspect ratio on heat transfer and friction in steam-cooled ducts with 60 angled rib Turbulators, Experimental Thermal and Fluid Science, 123-134(2013)

17. Gongnan Xie, Jian Liu, Weihong Zhang, Numerical Prediction of Turbulent Flow and Heat Transfer Enhancement in a Square Passage With Various Truncated Ribs on One Wall, Journal of Heat Transfer, 2014, 136,011902-1- 01190211(2014)

18. Mi-Ae Moon, Min-Jung Park, Kwang-Yong Kim, Evaluation of heat transfer performances of various rib shapes" International Journal of Heat and Mass Transfer, 71,275-284 (2014) 